\title{
Fast Stent Retrieval Improves Recanalization Rates of Thrombectomy: Experimental Study on Different Thrombi
}

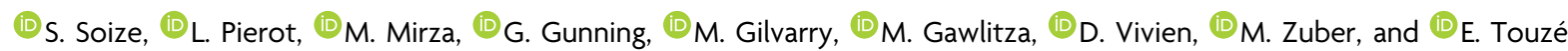

\section{ABSTRACT}

BACKGROUND AND PURPOSE: About $20 \%$ of patients with acute ischemic stroke due to large-artery occlusion do not achieve recanalization with mechanical thrombectomy. We aimed to determine whether the speed of retrieval of the stent retriever influences the efficacy in removing different clot types.

MATERIALS AND METHODS: Sixty mechanical thrombectomies were performed using an in vitro pulsatile cerebrovascular circulation model with controlled pressure and flow rate. Experiments were dichotomized into fast and slow retrieval using a wedging technique, in which the stent retriever and distal catheter are retrieved together. We used 3 different clot types: erythrocyte-rich, fibrin-rich, and friable clots. Primary end points were complete ( $\mathrm{TICl} 3)$ and successful $(\mathrm{TICl} 2 \mathrm{~b}-3)$ recanalizations. Secondary measures were distal and new territory embolizations.

RESULTS: Fast retrieval was more frequently associated with complete $(\mathrm{RR}=1.83 ; 95 \% \mathrm{Cl}, 1.12-2.99)$ and successful recanalization $(\mathrm{RR}=1.50 ; 95 \% \mathrm{Cl}, 1.03-2.19)$ than slow retrieval, without a difference in distal embolization $(\mathrm{RR}=0.75 ; 95 \% \mathrm{Cl}, 0.29-1.90)$. There were no emboli in a new territory. The advantage of fast retrieval over slow retrieval differed according to the clot composition, with a stronger effect with fibrin-rich clots with regard to complete (RR $=4.00 ; 95 \% \mathrm{Cl}, 1.11-14.35$; Pint $=.04)$ and successful $(P$ int $=.10)$ recanalization.

CONCLUSIONS: In our experimental model, a fast removal improved recanalization rates of mechanical thrombectomy, especially in the case of fibrin-rich clots. An in vivo confirmation is warranted to see whether our findings can have an impact in clinical practice.

ABBREVIATIONS: $\mathrm{DC}=$ distal catheter; $\mathrm{MT}=$ mechanical thrombectomy; $\mathrm{RR}=$ relative risk; $P$ int $=P$ interaction; $\mathrm{RBC}=$ red blood cell; $\mathrm{SR}=\mathrm{stent}$ retriever

M echanical thrombectomy (MT) is considered the first-line therapy for selected patients with acute ischemic stroke with a proximal cerebral artery occlusion. ${ }^{1-3}$ The dramatic technological improvements, such as the combined use of stent retrievers (SRs) and distal catheters (DCs), have led to recanalization rates unreached before. ${ }^{4,5}$ With the goal of increasing clot entrapment, techniques in which the thrombus is wedged between the SR and DC have become more popular. ${ }^{6-8}$ Nevertheless, a successful

Received January 17, 2020; accepted after revision March 2

From the Department of Neuroradiology (S.S., L.P., M. Gawlitza), Hôpital Maison Blanche, Champagne-Ardenne University, Reims, France; Unité Mixte de Recherche (UMR)-S 1237 Physiopathology and Imaging of Neurological Disorders (S.S., D.V., E.T.), National Institute for Health and Medical Research, Normandie University, Université Caen Normandie, Cyceron, Caen, France; Neuravi/Cerenovus (M.M., G.G., M. Gilvarry), Galway, Ireland; and Department of Neurology (M.Z.), Hôpital Saint-Joseph, Paris Descartes University, Paris, France.

Please address correspondence to Sebastien Soize, MD, Department of Neuroradiology, Hôpital Maison Blanche, 45 Rue Cognacq-Jay, Reims 51092, France; e-mail: ssoize@chu-reims.fr

Indicates article with supplemental on-line video.

http://dx.doi.org/10.3174/ajnr.A6559 recanalization is still not obtained in around $20 \%$ of patients. ${ }^{9}$ Potential issues may arise from the retrieval technique itself, the interactions between device-thrombus, and the clot composition. ${ }^{9,10}$ To date, only a few experimental studies have investigated th1053e interaction of the SR with artificial thrombi, ${ }^{11-18}$ and the influence of the retrieval speed on MT success has never been explored. The most instinctive approach to remove an SR is to pull it back slowly to save the vessel from potential damage and the clot from breaking. ${ }^{5,9}$ However, a fast removal can mobilize the clot suddenly and allow application of higher pulling force to enhance wedging. We aimed to determine whether the speed of retrieval influences the efficacy in removing clots.

\section{MATERIALS AND METHODS}

\section{Study Setting}

Using an in vitro model of cerebrovascular occlusion, we performed a total of 60 thrombectomy experiments (1 pass only for each), dichotomized into 2 groups according to the speed of retrieval of the SR-DC unit (fast or slow retrieval). The experiments were 
performed with 3 types of clots. Half of the tests were performed with Solitaire $2(4 \times 20 \mathrm{~mm})$ (Medtronic) and half with Embotrap II $(5 \times 21 \mathrm{~mm})$ (Neuravi/Cerenovus). Consequently, there were 2 speeds $\times 3$ types of clots $\times 5$ maneuvers each $\times 2$ devices, corresponding to $60 \mathrm{MTs}$ in total.

\section{Flow Model}

In brief, the model is made of silicone channels (Elastrat) mimicking the human anterior intracranial circulation. The flow model had sharp angles and large perforator diameters to create challenging conditions, and a posterior flow was also added for complete circle of Willis flow. A saline solution at $37^{\circ} \mathrm{C}$ was pumped through the model with a $430-\mathrm{mL} / \mathrm{min}$ flow rate and 110/60 $\mathrm{mm} \mathrm{Hg}$ pulsatile pressure. A fresh clot was introduced into the model to simulate the vessel occlusion (Fig 1).

\section{Clots Types}

We used 3 different types of clot depending on their composition (Fig 2): red blood cell (RBC)-rich, fibrin-rich, and hybrid clots (representing the challenges of a friable clot). The RBCrich clots were formed from whole ovine blood by allowing the blood to clot spontaneously. The fibrin-rich clots were prepared by first spinning down the blood sample in a centrifuge and recombining 5\% RBCs with $95 \%$ plasma to produce a fibrin-rich clot. ${ }^{19}$ Hybrid clots were prepared specifically to

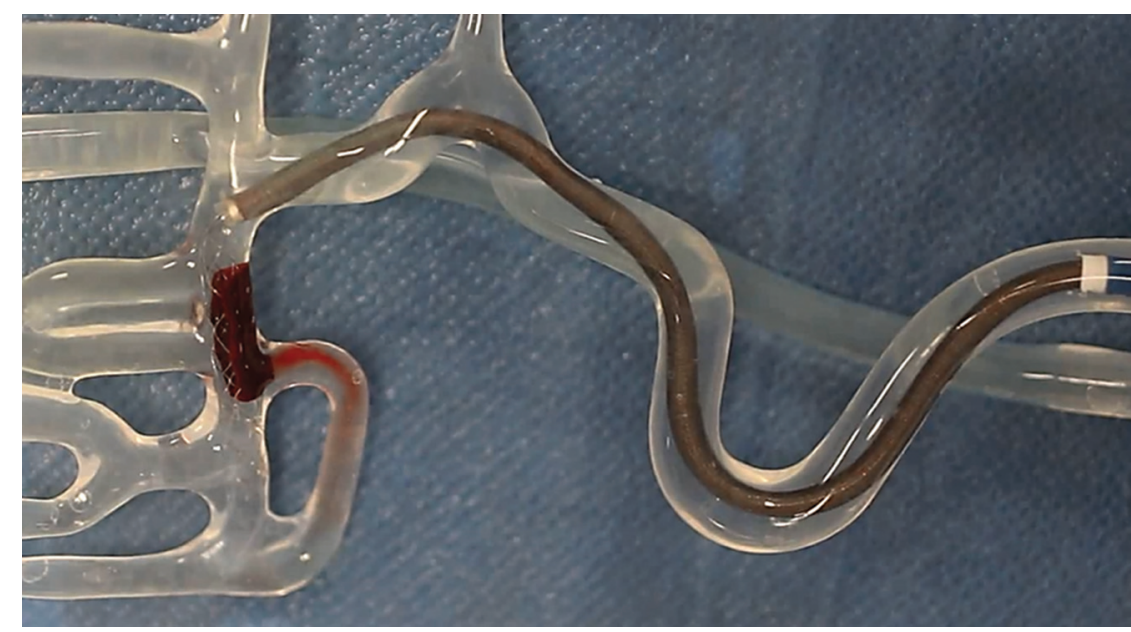

FIG 1. Flow model.
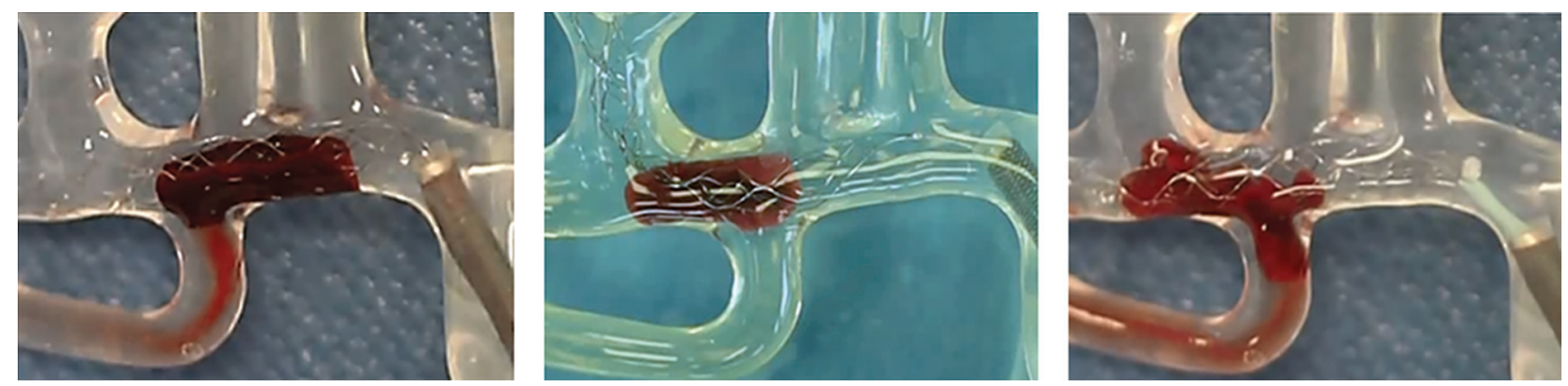

FIG 2. Clot types. The figure shows the 3 types of clot during MT inside the model: RBC-rich (left), fibrin-rich (middle), and hybrid friable clot (right). 

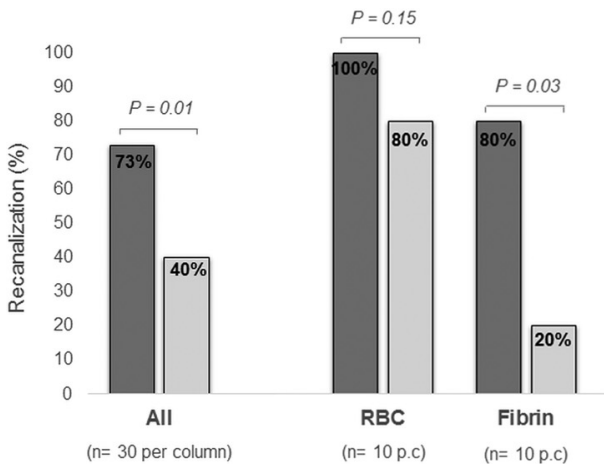

A

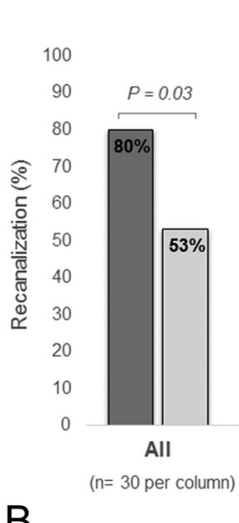

B
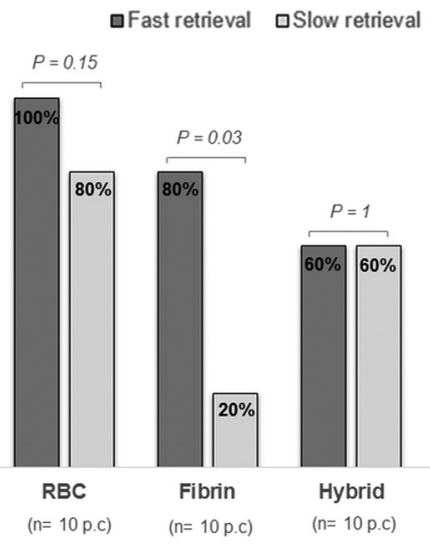

$\square$ Fast retrieval $\square$ Slow retrieval

FIG 3. Complete $(A)$ and successful $(B)$ recanalization rates.

corresponded to part of the initial thrombus migrating in the MCA territory farther than the distal limit of the model (ie, $<1.5 \mathrm{~mm}$ in diameter). Emboli in a new territory were any clots migrating into another area. Primary outcome measures were complete (TICI 3) and successful recanalization (TICI 2b-3). Secondary measures were distal and new territory emboli. All experiments were recorded and reviewed for verification purposes (On-line Videos).

\section{Statistical Analyses}

Distribution normality was assessed using the KolmogorovSmirnov test. Continuous variables were described as mean \pm $\mathrm{SD}$ or median and interquartile range and were compared using the Student $t$ test or Mann-Whitney $U$ test. Categoric variables were presented as counts and compared using the $\chi^{2}$ or Fisher exact test. Relative risks and their 95\% confidence intervals were calculated. Interaction analyses were performed using the Cochran-Mantel-Haenszel test. Analyses were performed using STATA software (Realease 15.0; StataCorp).

\section{RESULTS}

\section{Fast-versus-Slow Retrieval}

The mean time of retrieval was $2.4 \pm 1.2$ seconds in the fast group and $27.3 \pm 6.8$ seconds in the slow group $(P<.001)$. Overall, fast retrieval led to higher rates of complete (73\% versus $40 \%, P=.01)$ and successful $(80 \%$ versus $53 \%, P=.03)$

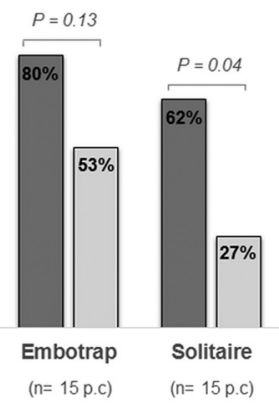

first-pass recanalization than slow retrieval. Fast retrieval was more frequently associated with complete (Relative Risk $=1.83$; 95\% CI, $1.12-$ 2.99) and successful first-pass recanalization ( $\mathrm{RR}=1.50$; 95\% CI, 1.03-2.19) than slow retrieval. Recanalization rates in the whole experiment as well as according to clot type and SR type are shown in Fig 3.

\section{Clot Composition}

The advantage of fast retrieval over slow retrieval differed according to the clot composition (Fig 4), with a stronger effect obtained with fibrinrich clots $(\mathrm{RR}=4.00$; $95 \% \mathrm{CI}, 1.11-$ 14.35) than with RBC-rich ( $\mathrm{RR}=$ 1.25; 95\% CI, 0.92-1.70) and hybrid friable $(\mathrm{RR}=2.00 ; 95 \% \mathrm{CI}, 0.47-$ 8.56) clots with regard to complete recanalization $(P$ int $=.04)$. This result was similar when considering successful recanalization instead $(P$ int $=.10)$ (Fig 2).

\section{SR Type}

The advantage of fast retrieval over slow retrieval did not differ according to the SR type (Fig 2) with regard to complete recanalization $($ Pint $=.32)$ or successful recanalization $($ Pint $=.19)($ Fig 4$)$.

\section{Distal Embolization}

Distal embolization occurred only with hybrid friable clots and was not different between fast (20.0\%) and slow (26.7\%) retrieval groups ( $\mathrm{RR}=0.75 ; 95 \% \mathrm{CI}, 0.29-1.90)$. There were no emboli in a new territory.

\section{DISCUSSION}

Our experimental study showed that a fast retrieval improves recanalization rates, without increasing the rate of distal embolization. It was all the more important that we measured the achievement of complete/successful revascularization after 1 pass, which is associated with significantly higher rates of good clinical outcome. $^{20-22}$ In this experimental study, we reached $73 \%$ and $80 \%$ of complete and successful recanalization with 1 pass, while in clinical routine, current thrombectomy techniques yield around $30 \%$ and $50 \%$ complete and successful recanalization, respectively. ${ }^{20-22}$ Although not instinctive, a fast removal can mobilize the clot suddenly, allow application of higher pulling force, enhance clot wedging, and minimize loss of apposition during the path of retrieval. Also, it may leave less time for variations of the pulling force, hence avoiding undesired loss of contact between SR and DC. A fast removal did not modify the rate of distal embolization, probably because of an active pinning of the whole thrombus length. 


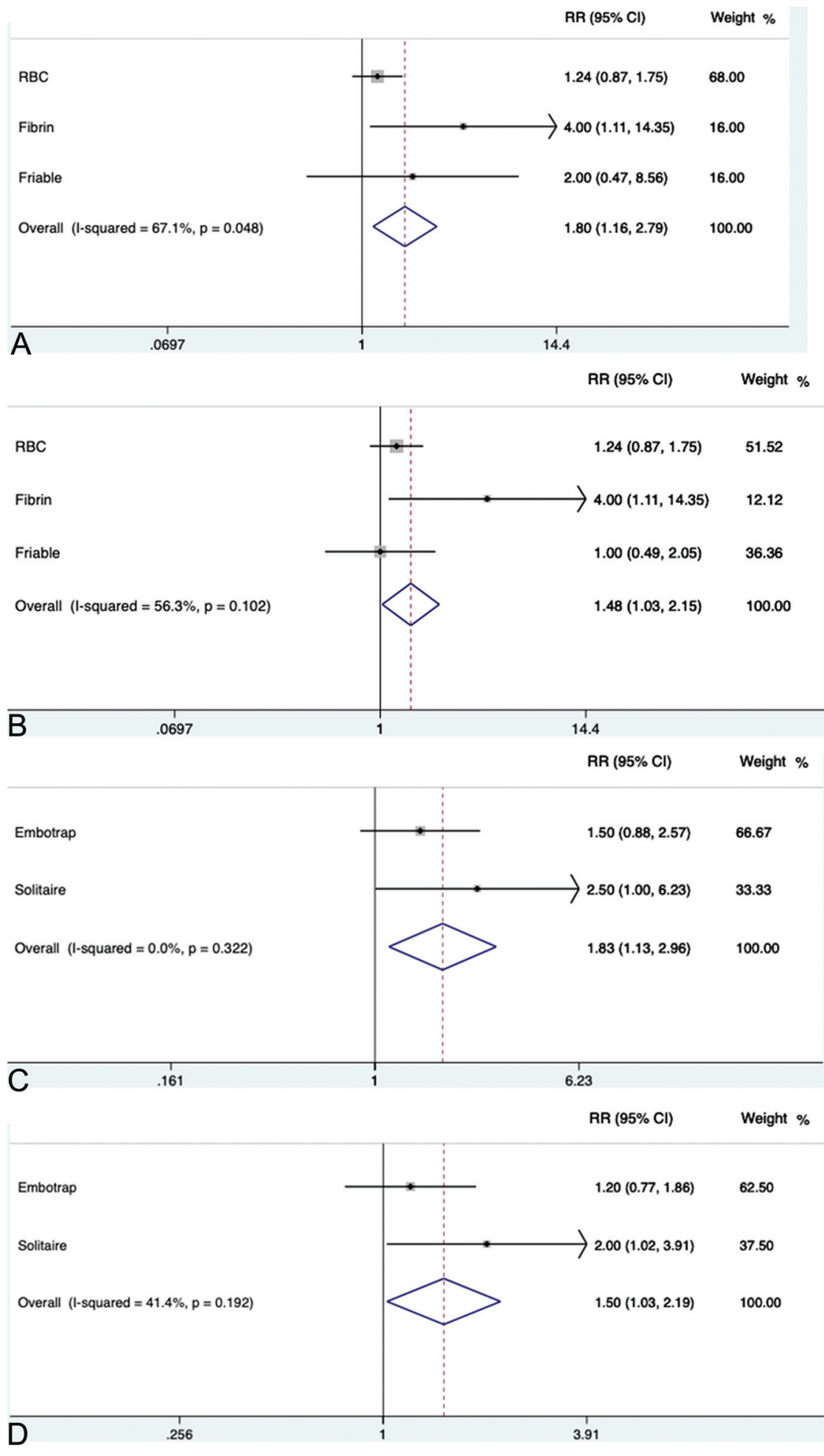

FIG 4. Interactions analyses. Interaction between the speed of retrieval and the clot type with regard to complete $(A)$ and successful $(B)$ recanalization. Interaction between the speed of retrieval and stent retriever type with regard to complete $(C)$ and successful $(D)$ recanalization. recommend slowly withdrawing the $\mathrm{SR}$ as a precaution for safety. When one performs a mechanical retrieval, the perforators may be exposed to excessive force due to stretching and may be rarely sheared off, leading to extravasation. A sudden mobilization of the clot may enhance its retrieval, but the effect on the lenticulostriate arteries is unknown. Thus, the safety of fast retrieval needs to be evaluated in vivo.

The composition and physical properties of the clot can play a key role in the response to $\mathrm{MT}^{9,23-25} \mathrm{We}$ observed a stronger advantage of fast over slow retrieval with fibrin-rich clots. These clots probably account for a large part of MT failures because they are firm and sticky. ${ }^{9,23,24}$ Fast retrieval, by mobilizing the clot suddenly, may have contributed to better clot trapping. Because imaging features of fibrin-rich thrombi are correlated with decreased revascularization rates, ${ }^{25,26}$ a fast retrieval might be recommended in such cases, to enhance first-pass revascularization. This is all the more important in that there is the potential for thrombus compression and increasing difficulty of subsequent retrieval after each thrombectomy attempt. ${ }^{9}$

Our study has potential limitations. First, the model and clots were more representative of embolic stroke types (not atherosclerosis). The circulation model does not fully simulate the human artery, and further in vivo studies are mandatory to confirm our results and evaluate the clinical safety. Also, tortuous anatomy probably has an impact that cannot be measured with our model. ${ }^{22}$ Second, because we aimed to analyze only factors attributable to the SR, we did not apply aspiration. In all the in vitro attempts, the DC was always in the M1 proximal part, covering the anterior cerebral artery and in the same axis as the clot. In such cases, the need for proximal aspiration was probably less important than when clot and DC are far away from each other (eg, distal M2 clot, or DC still in the ICA) or in
While fast retrieval seems promising in terms of recanalization, an important concern is the clinical safety of this technique. Indeed, human perforating arteries cannot be modeled accurately, and the risk of injury remains unknown. The manufacturers a very tortuous M1. Because only 1 specific procedural setup was simulated, it may not translate to other procedures (longer clots, techniques not similar to Aspiration-Retriever Technique for Stroke or stent-assisted vacuum-locked extraction (SAVE 
technique), and use of a baloon guide catheter). Such setups remain to be tested.

\section{CONCLUSIONS}

In our experimental model, a fast removal improved recanalization rates of MT, especially in case of fibrin-rich clots, which are known to be challenging to remove. An in vivo confirmation is warranted to see whether our findings can impact clinical practice.

Disclosures: Laurent Pierot-UNRELATED: Consultancy: Balt, MicroVention, phenox, Vesalio. Mahmood Mirza-UNRELATED: Employment: Cerenovus; Stock/ Stock Options: Cerenovus. Matthias Gawlitza-UNRELATED: Expert Testimony: MicroVention, Comments: member of the Clinical Event Committee for a company-initiated study on a neurovascular device; Travel/Accommodations/ Meeting Expenses Unrelated to Activities Listed: Neuravi/Cerenovus, phenox, MicroVention, Comments: travel and accommodations for training workshops of the respective companies; Other: Lin. Michael Gilvarry-UNRELATED: Employment: Cerenovus; Stock/Stock Options: Cerenovus.

\section{REFERENCES}

1. Powers WJ, Rabinstein AA, Ackerson T, et al; American Heart Association Stroke Council. 2018 Guidelines for the Early Management of Patients with Acute Ischemic Stroke: a Guideline for Healthcare Professionals From the American Heart Association/American Stroke Association. Stroke 2018;49:e46-10 CrossRef Medline

2. Mokin M, Ansari SA, McTaggart RA, et al; Society of NeuroInterventional Surgery. Indications for thrombectomy in acute ischemic stroke from emergent large vessel occlusion (ELVO): report of the SNIS Standards and Guidelines Committee. J Neurointerv Surg 2019;11:215-20 CrossRef Medline

3. Gandhi CD, Al Mufti F, Singh IP, et al; Standards and Guidelines committee of the Society of NeuroInterventional Surgery (SNIS). Neuroendovascular management of emergent large vessel occlusion: update on the technical aspects and standards of practice by the Standards and Guidelines Committee of the Society of NeuroInterventional Surgery. J Neurointerv Surg 2018;10:315-20 CrossRef Medline

4. Goyal M, Menon BK, van Zwam WH, et al. Endovascular thrombectomy after large-vessel ischaemic stroke: a meta-analysis of individual patient data from five randomised trials. Lancet 2016;387:172331 CrossRef Medline

5. Pierot L, Soize S, Benaissa A, et al. Techniques for endovascular treatment of acute ischemic stroke: from intra-arterial fibrinolytics to stent-retrievers. Stroke 2015;46:909-14 CrossRef Medline

6. Mokin M, Ionita CN, Nagesh SV, et al. Primary stentriever versus combined stentriever plus aspiration thrombectomy approaches: in vitro stroke model comparison. J Neurointerv Surg 2015;7:453-57 CrossRef Medline

7. Massari F, Henninger N, Lozano JD, et al. ARTS (AspirationRetriever Technique for Stroke): initial clinical experience. Interv Neuroradiol 2016;22:325-32 CrossRef Medline

8. Maus V, Behme D, Kabbasch C, et al. Maximizing first-pass complete reperfusion with SAVE. Clin Neuroradiol 2018;28:327-38 CrossRef Medline

9. Yoo AJ, Andersson T. Thrombectomy in acute ischemic stroke: challenges to procedural success. J Stroke 2017;19:121-30 CrossRef Medline
10. Kaesmacher J, Gralla J, Mosimann PJ, et al. Reasons for reperfusion failures in stent-retriever-based thrombectomy: registry analysis and proposal of a classification system. AJNR Am J Neuroradiol 2018;39:1848-53 CrossRef Medline

11. Gralla J, Schroth G, Remonda L, et al. Mechanical thrombectomy for acute ischemic stroke thrombus-device interaction, efficiency, and complications in vivo. Stroke 2006;37:3019-24 CrossRef Medline

12. Chueh JY, Wakhloo AK, Gounis MJ. Effectiveness of mechanical endovascular thrombectomy in a model system of cerebrovascular occlusion. AJNR Am J Neuroradiol 2012;33:1998-2003 CrossRef Medline

13. Wenger KJ, Nagl F, Wagner M, et al. Improvement of stent retriever design and efficacy of mechanical thrombectomy in a flow model. Cardiovasc Intervent Radiol 2013;36:192-97 CrossRef Medline

14. Mordasini P, Brekenfeld C, Byrne J, et al. Experimental evaluation of immediate recanalization effect and recanalization efficacy of a new thrombus retriever for acute stroke treatment in vivo. AJNR Am J Neuroradiol 2013;34:153-58 CrossRef Medline

15. Mokin M, Setlur Nagesh SV, Ionita CN, et al. Comparison of modern stroke thrombectomy approaches using an in vitro cerebrovascular occlusion model. AJNR Am J Neuroradiol 2015;36:547-51 CrossRef Medline

16. Madjidyar J, Hermes J, Freitag-Wolf S, et al. Stent-thrombus interaction and the influence of the aspiration on mechanical thrombectomy: evaluation of different stent retrievers in a circulation model. Neuroradiology 2015;57:791-97 CrossRef Medline

17. van der Marel K, Chueh JY, Brooks OW, et al. Quantitative assessment of device-clot interaction for stent retriever thrombectomy. $J$ Neurointerv Surg 2016;8:1278-82 CrossRef Medline

18. Machi P, Jourdan F, Ambard D, et al. Experimental evaluation of stent retrievers' mechanical properties and effectiveness. J Neurointerv Surg 2017;9:257-63 CrossRef Medline

19. Duffy S, Farrell M, McArdle K, et al. Novel methodology to replicate clot analogs with diverse composition in acute ischemic stroke. $J$ Neurointerv Surg 2017;9:486-91 CrossRef Medline

20. Zaidat $\mathrm{OO}$, Castonguay $\mathrm{AC}$, Linfante I, et al. First pass effect: a new measure for stroke thrombectomy devices. Stroke 2018;49:660-66 CrossRef Medline

21. Ducroux C, Piotin M, Gory B, et al. First pass effect with contact aspiration and stent retrievers in the Aspiration versus Stent Retriever (ASTER) trial. J Neurointerv Surg 2020;12:386-91 CrossRef Medline

22. Srivatsa S, Duan Y, Sheppard JP, et al. Cerebral vessel anatomy as a predictor of first-pass effect in mechanical thrombectomy for emergent large-vessel occlusion. J Neurosurg 2020 Jan 24. [Epub ahead of print] CrossRef Medline

23. Yuki I, Kan I, Vinters HV, et al. The impact of thromboemboli histology on the performance of a mechanical thrombectomy device. AJNR Am J Neuroradiol 2012;33:643-48 CrossRef Medline

24. Gunning GM, McArdle K, Mirza M, et al. Clot friction variation with fibrin content; implications for resistance to thrombectomy. $J$ NeuroIntervent Surg 2018;10:34-38 CrossRef Medline

25. Lövblad KO. Targeting the clot in acute stroke. AJNR Am J Neuroradiol 2018;39:E77 CrossRef Medline

26. Brinjikji W, Duffy S, Burrows A, et al. Correlation of imaging and histopathology of thrombi in acute ischemic stroke with etiology and outcome: a systematic review. J Neurointerv Surg 2017;9:529-34 CrossRef Medline 